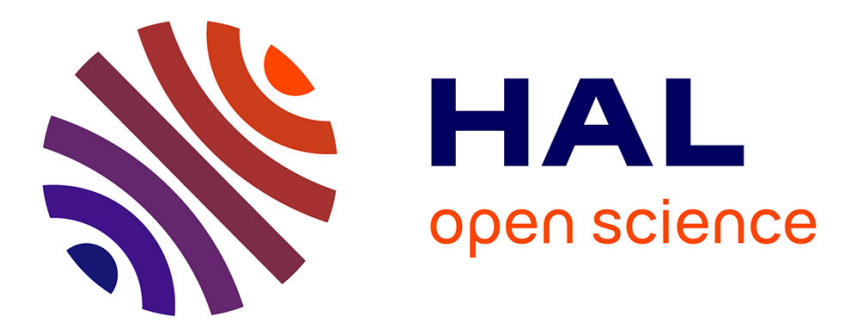

\title{
Dupuytren's disease: personal factors and occupational exposure.
}

Gérard Lucas, Anne Brichet, Yves Roquelaure, Annette Leclerc, Alexis

Descatha

\section{- To cite this version:}

Gérard Lucas, Anne Brichet, Yves Roquelaure, Annette Leclerc, Alexis Descatha. Dupuytren's disease: personal factors and occupational exposure.. American Journal of Industrial Medicine, 2008, 51 (1), pp.9-15. 10.1002/ajim.20542 . inserm-00225779

\section{HAL Id: inserm-00225779 https://www.hal.inserm.fr/inserm-00225779}

Submitted on 29 Mar 2013

HAL is a multi-disciplinary open access archive for the deposit and dissemination of scientific research documents, whether they are published or not. The documents may come from teaching and research institutions in France or abroad, or from public or private research centers.
L'archive ouverte pluridisciplinaire HAL, est destinée au dépôt et à la diffusion de documents scientifiques de niveau recherche, publiés ou non, émanant des établissements d'enseignement et de recherche français ou étrangers, des laboratoires publics ou privés. 


\section{HAL author manuscript}

\section{Dupuytren's disease: personal factors and occupational exposure}

Gérard Lucas $\left({ }^{1}\right)$, Anne Brichet $\left({ }^{1}\right)$, Yves Roquelaure $\left({ }^{2}\right)$ Annette Leclerc $\left({ }^{3}\right)$, Alexis Descatha $\left({ }^{3,4}\right)$

${ }^{1}$ DRTEFP, Pays-de-Loire et Bretagne, France;

${ }^{2}$ Laboratory of Epidemiology, Ergonomics and Occupational Health, Angers, F-49000, France;

${ }^{3}$ INSERM, U687, Saint-Maurice, F-94410, France ; Université Paris XI, IFR69, Villejuif, F94807, France ; Université Versailles-Saint Quentin, Faculté de Médecine Paris-Ile-deFrance-Ouest, France;

${ }^{4}$ AP-HP, Occupational health department, Poincaré teaching hospital, Garches, F-92380, France;

Correspondence and reprints. Alexis Descatha, Unité de pathologie professionnelle, Hôpital Raymond Poincaré, AP-HP, 92380 Garches, France Tel: +33 (1) 471077 54; Fax: +33 (1) 471077 68; email: alexis.descatha@rpc.aphp.fr Running Title. Risk factors of Dupuytren's disease

Word count: 2325 words (abstract, reference list and tables excluded). 


\section{Dupuytren's disease: personal factors and occupational exposure}

\section{ABSTRACT (195 words)}

Background. The etiology of Dupuytren's disease is unknown, and the role of occupational exposure is still debated. Our objective was to study the association between occupational exposures, personal risk factors and Dupuytren's disease.

Methods. In this cross-sectional survey, nine occupational physicians performed clinical examinations, focused on Dupuytren's disease, of 2,406 French male civil servants employed at the Equipment Ministry in 1998 and interviewed them about medical history, leisure manual exposure and occupational biomechanical exposure to vibrations and manual work. A cumulative occupational exposure score was defined, with three levels of exposure.

Results. Dupuytren's disease was diagnosed in 212 men (8.8\%). The occupational exposure score was significantly higher in this group of cases than in the rest of the sample (377 (SD280) versus 223 (SD250), respectively; $\mathrm{p}<0.0001$ ). Occupational exposure was associated with Dupuytren's disease (adjusted Odds Ratio=2.20[1.39-3.45] for the intermediate and 3.10 [1.99-4.84] for the high exposure groups), with adjustment for age, leisure physical activities, alcohol consumption ( $\geq 5$ servings per day), history of diabetes, epilepsy, hand trauma, and familial history of Dupuytren's disease.

Conclusion. Manual work exposure was associated with Dupuytren's disease after adjustment for personal risk factors. Longitudinal studies are needed to confirm these results.

Keywords. Dupuytren's Contracture, Risk Factors, Occupational Disease. 


\section{INTRODUCTION}

Dupuytren's disease is characterized by chronic contracture of the fourth and fifth fingers of the hand toward the palm, usually accompanied by ridging of the palmar skin (Calif and Stahl 2007). This abnormality has been reported in the medical literature since the early 1600 s (Dembe 1996). Baron Guillaume Dupuytren, in his presentation of December 5, 1831, at the Hotel-Dieu in Paris, clearly identified the disorder's lesion as contracture of the palmar fascia, which he asserted could be surgically treated by excision of the palmar aponeurosis. Although one of the earliest references to the relation between this disease and occupational activities dates back to that conference, its etiology remains unknown today and the role of occupational exposure is still debated (Townley et al. 2006). In most studies, exposure was assessed as manual work versus non manual, based on job title (Early 1962; Chanut 1963; Khan et al. 2004;Attali et al. 1987;Bennett 1982;Gudmundsson et al. 2000;Hueston 1968; Liss and Stock 1996;Galimard et al. 2006). Two studies with a more precise assessment of exposure did not take into account personal factors, such as alcohol consumption, diabetes mellitus, epilepsy or anticonvulsant drug intake, hand trauma, family history of Dupuytren's disease (Mikkelsen 1978; de la Caffiniere et al. 1983). Only two studies had considered both occupational and personal risk factors, with a precise assessment of exposure of vibrations but without taking into account other occupational factors (Bovenzi 1994;Cocco et al. 1987).

Our objective was to study the association between occupational exposure, personal risk factors and Dupuytren's disease in a cross-sectional survey of French men in the regions of Pays de la Loire and Brittany. 


\section{METHODS}

\section{Population}

In 1998, nine of the twelve occupational physicians at the Ministry of Equipment in these regions included all of the male civil servants they saw that year in this study in their usual work. In France, occupational physicians are responsible for monitoring occupational exposures and performing annual health examinations, which are mandatory for all workers. Workers could refuse the statistical analyses of their personal data and the France's national committee for data protection was informed of the study (CNIL: Commission Nationale Informatique et Liberté).

\section{Exposure}

Physicians conducted a structured interview to obtain subjects' age and biomechanical exposure and medical history.

Work tasks defined as entailing biomechanical exposure were : (i) using a tool with handle, (ii) using a vibrating tool, (iii) manual handling, and (iv) repairing mechanical equipment. Subjects were asked separately about whether they performed each task, for how many years they had done so, and for each of those years, if they were exposed for less than one month a year, from one to six months, or six months or more.

A score for each exposure was constructed to estimate the total duration of lifetime occupational exposure, expressed in months. The number of years worked was multiplied by an estimate of average annual frequency, assessed as 0.5 for exposure less than one month per year, 3 for one to less than six months, and 8 for six to twelve months. The total exposure score was the sum of the four lifetime scores, one for each defined task. For instance, a man who worked daily for 20 years with vibrating tools (every day $=8$; contribution to the score 
$8 \times 20=160$ ), manual handling (idem) and used a tool with handle (idem) had a score of 480 . This score ranged from 0 to 1344 (mean 237, median 168, standard deviation (SD) 257); 25\% of the workers had a score of 421 or more, $33 \%$ a score of 326 of more and $33 \%$ were not exposed (score $=0)$.

Three occupational exposure categories were defined: exposure scores of 0 were low-level exposure; scores from 0.5 to 400 intermediate; and a score over 400 high.

An alternative to a global score was considering separately four sub-scores: using a tool with handle, using a vibrating tool, manual handling, and repairing mechanical equipment. Preliminary analyses indicated that the level of exposure to each of these risk factors was significantly higher among cases of Dupuytren's disease. However, a global score was preferred because the levels of exposure to the four risk factors were highly correlated.

The physician inquired about and assessed leisure activities involving the same biomechanical exposures in the same way.

The clinical examination began with a medical history, including history of diabetes mellitus, epilepsy (or anticonvulsant drug intake) and hand trauma, as well as familial history of Dupuytren's disease. Physicians also asked about alcohol consumption and noted those subjects drank more than 5 servings daily.

The presence of a personal risk factor (any one of history of diabetes mellitus, epilepsy or anticonvulsant drug intake, or hand trauma, family history of Dupuytren's disease, or alcohol consumption of 5 servings/day or more, compared with none) was also considered.

\section{Diagnosis}


The physical examination looked for clinical signs of thickening of the palmar fascia and/or flexion contracture in phalanx $2,3,4$ or 5 .

\section{Statistical analysis}

Data were anonymized, entered, and analyzed with SAS software (SAS v8.2, SAS Institute Inc, Cary, NC, USA). Bivariate analyses used Student $t$ and chi-square tests, and multivariate analysis used logistic models, where risk factors were entered into the model all together. Interactions between personal and occupational factors were tested (Proc Logistic under SAS software). Associations were considered significant if the p-value was less than 0.05 . 


\section{RESULTS}

The study included 2,406 male civil servants seen in 1998 (less than five percent refused to be included the study). With 212 men suffering from Dupuytren's disease, the point prevalence was 8.8 percent. Case subjects, that is, those diagnosed with Dupuytren's disease, were older on average than those not so diagnosed (50.7 years (SD 5.4) versus 44.8 years (SD 7.6), degree of freedom (DF) 2404, value of $\mathrm{t} 11.05, \mathrm{p}<0.0001$ ). Table I reports the bivariate associations: all of the suspected personal and occupational factors were associated with disease prevalence. The occupational exposure score was significantly higher among case subjects (377 (SD 280) versus 223 (SD 250), DF 2404, value of t 8.47, p<0.0001).

Disease prevalence according to occupational exposure category was studied separately for subgroups based on the presence or absence of personal factors (Table II). In all situations, prevalence increased with level of occupational exposure. The crude Odds Ratio (OR) associated with occupational exposure had quite similar magnitude among those exposed or not to personal factors and all the interaction tests between these factors were not significant (Table III). This implies that the effects can be considered as multiplicative.

Both personal and occupational risk factors were associated with Dupuytren's disease in the multivariate analysis (borderline significance for history of diabetes mellitus), with a dose effect for occupational exposure (adjusted OR of 2.20 for intermediate level and of 3.10 for high exposure level in the detailed model, Table IV). 


\section{DISCUSSION}

\section{Main results}

This is one of the first studies of Dupuytren's disease in the workplace to take occupational and most of the clearly established personal risk factors into account (Galimard et al. 2006). It is also one of the first to include a precise quantitative assessment of occupational exposure, especially for manual work (Liss and Stock 1996).

\section{Limitations and strength of the study}

The first limitation in this study is the cross-sectional design and exposure assessment by questionnaire. Workers with Dupuytren's disease may be more likely to describe their work as strenuous. To avoid such recall bias, exposure was assessed by the occupational physicians, who knew the workers and their jobs. In addition, the relative precision of the questions should have limited recall bias.

The population was composed of male civil servants in the Ministry of Equipment assigned to Brittany and the Pays de la Loire. Men were chosen because the disease mainly affects men, and most workplace studies have focused on male workers (Mikkelsen 1978;Gudmundsson et al. 2000;de la Caffiniere et al. 1983;Chanut 1963;Bovenzi 1994;Thomas and Clarke 1992;Khan et al. 2004). This population was selected precisely because the occupation physicians in this French department had observed many cases of Dupuytren's disease in their working populations and decided to participate in the study by including it in their daily work for a year. Three lacked the time to participate. This is not expected to lead to a bias, since all the occupational physicians are in charge of similar samples of workers. Since the annual medical examination by the occupational physicians is compulsory, the study includes all the civil servants surveyed by the occupational physicians during the year, except those who 
refused to be included the study (less than five percent). Globally, the sample in this study can be considered as representative of the target population. Prevalence in the literature varies from 1 to 20 percent, depending on the population, which may range from those whose work involves no biomechanical exposure to older and highly exposed populations (Galimard et al. 2006). The prevalence of Dupuytren's disease in this study was similar to that in the Reykjavik cross-sectional survey, estimated at 10.5 percent among men in the 45-59-year age group (Gudmundsson et al. 2000) and to that in the cross-sectional study by Mikkelsen (9.3 percent) (Mikkelsen 1978).

Our study did not consider tobacco consumption. The role of smoking habits in Dupuytren's disease was not clearly shown until after this study was designed. Since then, two studies have concluded that tobacco consumption is a risk factor: a cross sectional study in 1997 and a prospective study in 2004, both of which also adjusted for other personal risk factors (Burge et al. 1997;Godtfredsen et al. 2004). However, neither study took precisely occupational risk factors into account (Galimard et al. 2006): Burge et al did not recorded occupational exposure; Godtfredsen et al only studied the proportion of physical activities at work (not significantly associated with Dupuytren's disease), and low education level (considered by authors as a proxy of manual work and significantly associated with Dupuytren's disease) (Burge et al. 1997; Godtfredsen et al. 2004).

\section{Association between personal factors and Dupuytren's disease}

This study demonstrates the association between personal risk factors and Dupuytren's disease. Most studies report positive associations between Dupuytren's disease and alcohol intake (Zerajic and Finsen 2004;Attali et al. 1987;Bradlow and Mowat 1986;Burge et al. 1997;Noble et al. 1992;Godtfredsen et al. 2004), age (Gudmundsson et al. 2000;Godtfredsen et al. 2004), diabetes mellitus (Gudmundsson et al. 2000;Godtfredsen et al. 2004;Geoghegan 
et al. 2004), familial history of Dupuytren's disease (Townley et al. 2006), and hand trauma (Attali et al. 1987;Mikkelsen 1978;Livingstone and Field 1999;Hueston 1968). The role of epilepsy and anticonvulsant drug intake, however, remains controversial (Geoghegan et al. 2004; Thurston 2003), although studies have found a high prevalence of Dupuytren's disease in patients with epilepsy (Arafa et al. 1992; Critchley et al. 1976).

\section{Association between occupational factors and Dupuytren's disease}

We found that manual work was significantly associated with Dupuytren's disease and observed a clear dose-response relation, with an aOR of 1.75 for manual hobbies, of 2.2 for an intermediate manual occupational exposure category, and of 3.1 for the high exposure category. Manual labor, including hand vibration exposure and manual handling was one of the first causes of occupational disease discussed in the medical literature (Dembe 1996). However, the role of manual occupational exposure as a risk factor for this disease is still debated (Townley et al. 2006).

In a study about hand-arm vibration syndrome in working Italian men, Bovenzi et al. observed a significant association between vibration and Dupuytren's disease $(\mathrm{aOR}=2.6$ [1.24-5.49], adjusted for age, alcohol and tobacco consumption (Bovenzi 1994)). Cocco et al. found that a history of vibration exposure was more frequent among case subjects than controls (Cocco et al. 1987). Similarly, Thomas et al. found a significant association between hand-arm vibration syndrome and Dupuytren's disease with a dose-response relation, but no relation to the severity of the hand-arm vibration syndrome (Thomas and Clarke 1992). These studies led Liss et al. to conclude that there is a good support for an association between vibration exposure and Dupuytren's disease (Liss and Stock 1996).

Some studies report no significant association between this disease and either handling or gripping with force. In 2004, a study using data from the National Morbidity Survey in 
England and Wales found that manual occupational social class was not associated with an increased incidence of Dupuytren's disease (Khan et al. 2004). Two other studies reported prevalence was similar in groups of manual and non-manual workers (Early 1962; Chanut 1963). All three studies, however, limited exposure assessment to a yes/no question. Some specific exposure associated with manual handling in this population might increase the risk of Dupuytren's disease more than other exposures in manual workers and thus explain our results. For example, some of these workers excavate trenches with pickaxes or clear bushes from spring through autumn, with a billhook before the 1980s and with a brush cutter after. Mikkelsen et al. distinguished different levels of occupational exposure and found a clear dose-response relation between manual work and Dupuytren's disease, with a prevalence in the high exposure group similar to our results (15 percent in their study and 16 percent in ours). Bennett et al. found a lower prevalence than we did in both the low (prevalence 1 percent) and high (7 percent) exposure groups (Bennett 1982). De la Caffiniere et al found hard manual labor over many years was correlated with Dupuytren's disease, especially in the younger age group (de la Caffiniere et al. 1983). In the Reykjavik study, Gudmundsson et al found a prevalence of Dupuytren's disease among male manual workers (including manual laborers, seamen and farmers) and in tradesmen (carpenters, blacksmiths, and masons) of 15 percent compared with 6 percent in other occupations (with university degrees) (Gudmundsson et al. 2000). Manual workers and tradesmen had an OR for Dupuytren's disease significantly higher than all other men in the study.

\section{Conclusion}

In conclusion, our study found that after consideration of personal risk factors, manual work exposure appears to be associated with Dupuytren's disease. Longitudinal studies are needed 
to confirm these results with precise details about the kinds of physical exposure involved and taking tobacco intake into account.

\section{ACKNOWLEDGMENTS}

The study was supported by the AREEO and the West Occupational Health Society for the data collection and management.

We are grateful to the other occupational physicians involved in the examination: Drs Cazenave N., Chatelier F., Fichou A., Lucas M., Parentoine S., Peslerbes F., Roesch B., and Sabarly A.

We are also grateful to all the contributors to the study: Derriennic F., Saurel M.J., the UER of Angers, Bidron P., Mollat F., Ravalet G., Burgère D., the AREEO, the West Occupational Health Society and the French Ministry of Work.

We also thank Jean François Chastang for his contribution to the statistical analyses. 


\section{REFERENCES}

Arafa M, Noble J, Royle SG, Trail IA, Allen J. 1992. Dupuytren's and epilepsy revisited. J Hand Surg [Br] 17:221-224.

Attali P, Ink O, Pelletier G, Vernier C, Jean F, Moulton L, Etienne JP. 1987. Dupuytren's contracture, alcohol consumption, and chronic liver disease. Arch Intern Med 147:1065-1067.

Bennett B. 1982. Dupuytren's contracture in manual workers. Br J Ind Med 39:98-100.

Bovenzi M. 1994. Hand-arm vibration syndrome and dose-response relation for vibration induced white finger among quarry drillers and stonecarvers. Italian Study Group on Physical Hazards in the Stone Industry. Occup Environ Med 51:603-611.

Bradlow A, Mowat AG. 1986. Dupuytren's contracture and alcohol. Ann Rheum Dis 45:304307.

Burge P, Hoy G, Regan P, Milne R. 1997. Smoking, alcohol and the risk of Dupuytren's contracture. J Bone Joint Surg Br 79:206-210.

Calif E, Stahl S. 2007. Dupuytren's Contracture. N Engl J Med 356:e11.

Chanut JC. 1963. [Dupuytren's disease.]. Arch Mal Prof 24:621-625.

Cocco PL, Frau P, Rapallo M, Casula D. 1987. [Occupational exposure to vibration and Dupuytren's disease: a case-controlled study]. Med Lav 78:386-392.

Critchley EM, Vakil SD, Hayward HW, Owen VM. 1976. Dupuytren's disease in epilepsy: result of prolonged administration of anticonvulsants. J Neurol Neurosurg Psychiatry 39:498503.

de la Caffiniere JY, Wagner R, Etscheid J, Metzger F. 1983. [Manual labor and Dupuytren disease. The results of a computerized survey in the field of iron metallurgy]. Ann Chir Main 2:66-72.

Dembe A. 1996. Occupation and Disease: How Social Factors Affect the Conception of Work-Related Disorders. Yale, CT: Yale University Press.

Early PF. 1962. Population studies in Dupuytren's contracture. J Bone Joint Surg 44B:602-12.

Galimard N, Schnitzler A, Descatha A, Ameille J. 2006. Dupuytren's disease and manual work, can they be related? Review of literature. Arch Mal Prof 66:505-12.

Geoghegan JM, Forbes J, Clark DI, Smith C, Hubbard R. 2004. Dupuytren's disease risk factors. J Hand Surg [Br ] 29:423-426.

Godtfredsen NS, Lucht H, Prescott E, Sorensen TI, Gronbaek M. 2004. A prospective study linked both alcohol and tobacco to Dupuytren's disease. J Clin Epidemiol 57:858-863.

Gudmundsson KG, Arngrimsson R, Sigfusson N, Bjornsson A, Jonsson T. 2000.

Epidemiology of Dupuytren's disease: clinical, serological, and social assessment. The Reykjavik Study. J Clin Epidemiol 53:291-296. 
Hueston JT. 1968. Dupuytren's contracture and specific injury. Med J Aust 1:1084-1085.

Khan AA, Rider OJ, Jayadev CU, Heras-Palou C, Giele H, Goldacre M. 2004. The role of manual occupation in the aetiology of Dupuytren's disease in men in England and Wales. $\mathbf{J}$ Hand Surg [Br ] 29:12-14.

Liss GM, Stock SR. 1996. Can Dupuytren's contracture be work-related?: review of the evidence. Am J Ind Med 29:521-532.

Livingstone JA, Field J. 1999. Algodystrophy and its association with Dupuytren's disease. J Hand Surg [Br ] 24:199-202.

Mikkelsen OA. 1978. Dupuytren's disease--the influence of occupation and previous hand injuries. Hand 10:1-8.

Noble J, Arafa M, Royle SG, McGeorge G, Crank S. 1992. The association between alcohol, hepatic pathology and Dupuytren's disease. J Hand Surg [Br ] 17:71-74.

Thomas PR, Clarke D. 1992. Vibration white finger and Dupuytren's contracture: are they related? Occup Med (Lond) 42:155-158.

Thurston AJ. 2003. Dupuytren's disease. J Bone Joint Surg Br 85:469-477.

Townley WA, Baker R, Sheppard N, Grobbelaar AO. 2006. Dupuytren's contracture unfolded. BMJ 332:397-400.

Zerajic D, Finsen V. 2004. Dupuytren's disease in Bosnia and Herzegovina. An epidemiological study. BMC Musculoskelet Disord 5:10. 


\begin{tabular}{|c|c|c|c|c|c|c|c|}
\hline \multirow{2}{*}{ TOTAL } & & & $\begin{array}{c}\text { Number of } \\
\text { subjects }\end{array}$ & $\begin{array}{c}\text { Number of } \\
\text { cases }\end{array}$ & $\begin{array}{c}\text { Prevalence } \\
\% \\
\end{array}$ & OR $[95 \% \mathrm{CI}]$ & $\begin{array}{c}p= \\
\left(\text { chi }^{2} \text { test }\right)\end{array}$ \\
\hline & & & 2406 & 212 & 8.8 & & \\
\hline \multirow{11}{*}{$\begin{array}{l}\text { Occupation } \\
\text { exposures }\end{array}$} & \multirow{4}{*}{$\begin{array}{l}\text { Using a tool } \\
\text { with handle* } \\
\text { Using a } \\
\text { vibrating tool }\end{array}$} & No & 1070 & 54 & 5.1 & 1 & $<0.0001$ \\
\hline & & Yes & 1336 & 158 & 11.8 & $2.5[1.8-3.5]$ & \\
\hline & & No & 1746 & 131 & 7.5 & 1 & $<0.001$ \\
\hline & & Yes & 660 & 81 & 12.3 & $1.7[1.3-2.3]$ & \\
\hline & \multirow{2}{*}{$\begin{array}{l}\text { Manual } \\
\text { handling * }\end{array}$} & No & 915 & 49 & 5.4 & 1 & $<0.0001$ \\
\hline & & Yes & 1491 & 163 & 10.9 & $2.2[1.6-3.0]$ & \\
\hline & \multirow{2}{*}{$\begin{array}{l}\text { Repairing } \\
\text { mechanical } \\
\text { equipment * }\end{array}$} & No & 1604 & 139 & 8.0 & 1 & \\
\hline & & Yes & 590 & 73 & 11.0 & $1.4[1.1-1.9]$ & $<0.05$ \\
\hline & \multirow{3}{*}{$\begin{array}{l}\text { Work exposure } \\
\text { groups }\end{array}$} & Low level & 783 & 33 & 4.2 & 1 & $<0.0001$ \\
\hline & & Medium level & 979 & 73 & 7.5 & & $<0.0001 * *$ \\
\hline & & High level & 643 & 106 & 16.5 & & \\
\hline \multirow{2}{*}{\multicolumn{2}{|c|}{ Leisure manual activities }} & No & 1229 & 66 & 5.4 & 1 & $<0.0001$ \\
\hline & & Yes & 1177 & 146 & 12.4 & $2.5[1.8-3.4]$ & \\
\hline \multirow{12}{*}{$\begin{array}{l}\text { Personal } \\
\text { factors }\end{array}$} & \multirow{2}{*}{$\begin{array}{l}\text { Familial } \\
\text { history of } \\
\text { Dupuytren's } \\
\text { disease }\end{array}$} & No & 2186 & 168 & 7.7 & 1 & $<0.0001$ \\
\hline & & Yes & 220 & 44 & 20.0 & $3.0[2.1-4.3]$ & \\
\hline & \multirow{2}{*}{$\begin{array}{l}\text { History of } \\
\text { diabetes } \\
\text { mellitus }\end{array}$} & No & 2354 & 198 & 8.4 & 1 & $<0.0001$ \\
\hline & & Yes & 52 & 14 & 26.9 & $4.0[2.1-7.5]$ & \\
\hline & \multirow{2}{*}{$\begin{array}{l}\text { History of } \\
\text { epilepsy **** }\end{array}$} & No & 2390 & 206 & 8.6 & 1 & $<0.0001$ \\
\hline & & Yes & 16 & 6 & 37.5 & $6.4[2.3-17.7]$ & \\
\hline & \multirow{2}{*}{$\begin{array}{l}\text { History of } \\
\text { hand } \\
\text { traumatism }\end{array}$} & No & 2007 & 164 & 8.2 & 1 & $<0.05$ \\
\hline & & Yes & 399 & 48 & 12.0 & $1.5[1.1-2.2]$ & \\
\hline & \multirow{2}{*}{$\begin{array}{l}\text { Alcohol } \\
\text { consumption } \\
\geq 5 \text { drinks/day }\end{array}$} & No & 2043 & 146 & 7.2 & 1 & $<0.0001$ \\
\hline & & Yes & 363 & 66 & 18.2 & $2.9[2.1-4.0]$ & \\
\hline & \multirow{2}{*}{$\begin{array}{l}\text { Any personal } \\
\text { factors }\end{array}$} & No & 1822 & 120 & 6.6 & 1 & $<0.0001$ \\
\hline & & Yes & 584 & 92 & 15.8 & $2.7[2.0-3.5]$ & \\
\hline
\end{tabular}

Table I: Potential risk factors for Dupuytren' s disease, bivariate analyses.

* using a tool with handle, using a vibrating tool, manual handling and repairing mechanical equipment are defined broadly here, to mean at least once during the year

** tendency test $\quad * * *$ or anticonvulsant drug intake

$O R=$ odds ratios, $C I=$ confidence interval,$n s=p>0.05$ 


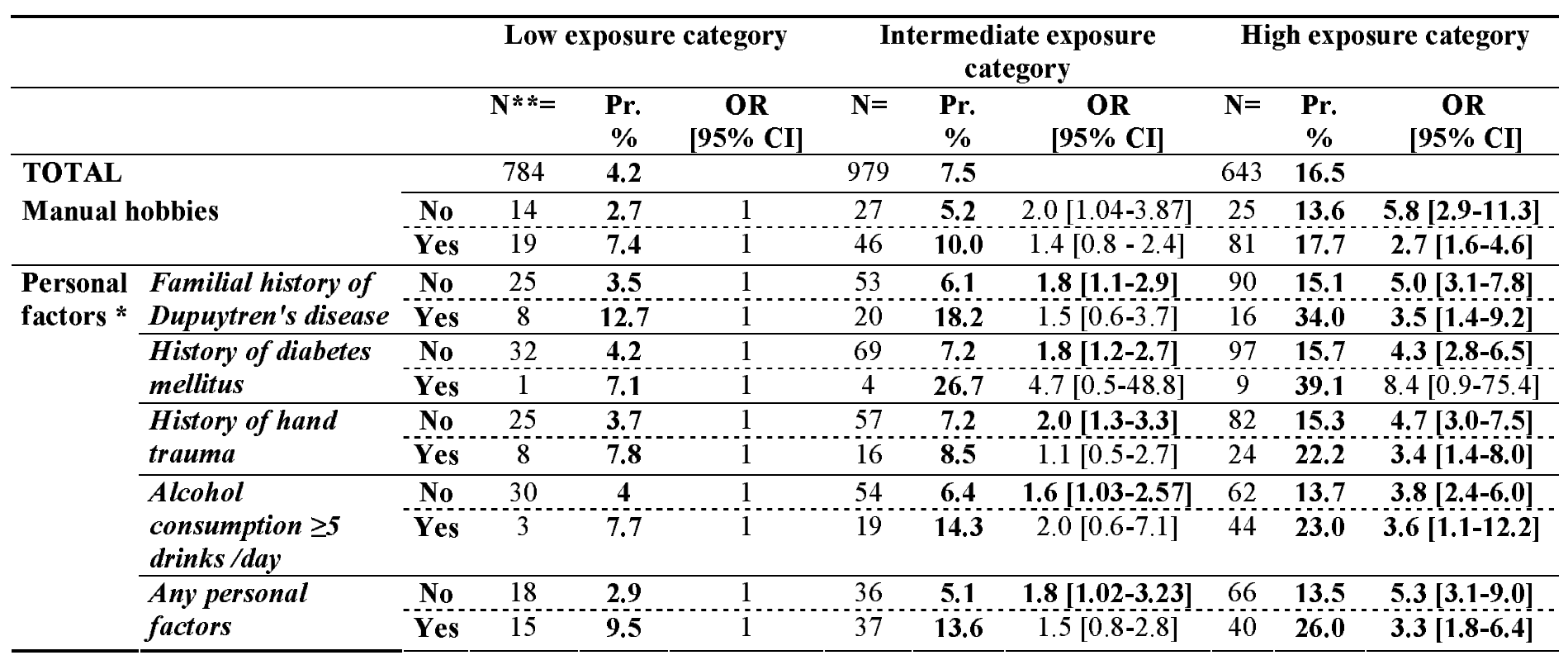

Table II: Prevalence (Pr.) and crude Odds Ratios (OR) for occupational factors

(compared to subjects with low exposure) in subjects with and without each personal

factor.

* No stratification on history of epilepsy or anticonvulsant drug intake, due to small number of cases $(n=16)$.

$N^{* *}=$ number of cases in the group, $C I=$ confidence interval 


\begin{tabular}{lcc}
\hline & OR [95\%CI] & $p=$ \\
\hline Intermediate work exposure *age & $1.03[0.96-1.10]$ & 0.45 \\
High work exposure*age & $1.01[0.94-1.08]$ & 0.84 \\
\hline Intermediate work exposure*manual hobbies & $0.70[0.29-1.65]$ & 0.41 \\
High work exposure* manual hobbies & $0.47[0.20-1.11]$ & 0.08 \\
\hline Intermediate work exposure*familial history of Dupuytren's disease & $0.86[0.31-2.37]$ & 0.77 \\
High work exposure*familial history of Dupuytren's disease & $0.73[0.25-2.10]$ & 0.56 \\
\hline Intermediate work exposure*history of diabetes mellitus & $2.66[0.25-28.53]$ & 0.42 \\
High work exposure*history of diabetes mellitus & $1.95[0.21-18.33]$ & 0.56 \\
\hline Intermediate work exposure*history of hand trauma & $0.54[0.20-1.48]$ & 0.23 \\
High work exposure*history of hand trauma & $0.71[0.27-1.88]$ & 0.50 \\
\hline Intermediate work exposure*alcohol consumption $\geq \mathbf{5}$ drinks /day & $1.23[0.32-4.77]$ & 0.76 \\
High work exposure*alcohol consumption $\geq 5$ drinks /day & $0.95[0.26-3.50]$ & 0.94 \\
\hline Intermediate work exposure *personal factors & $0.83[0.35-1.95]$ & 0.67 \\
High work exposure *personal factors & $0.63(0.27-1.47]$ & 0.29 \\
\hline
\end{tabular}

Table III. Interaction study between work exposure and each other factor separately.

* The interaction with history of epilepsy or anticonvulsant drug intake, due to small number of cases $(n=16)$, could not be studied.

$O R=$ odds ratios. $C I=$ confidence interval 


\begin{tabular}{|c|c|c|c|c|c|}
\hline & & \multicolumn{2}{|c|}{ "Detailed model" } & \multicolumn{2}{|c|}{ "Interaction model" } \\
\hline & & $\operatorname{aOR}[95 \% \mathrm{CI}]$ & $\mathbf{p}=$ & $\operatorname{aOR}[95 \% \mathrm{CI}]$ & $\mathbf{p}=$ \\
\hline Age & - & $1.15[1.12-1.19]$ & $<0.0001$ & $1.15[1.12-1.18]$ & $<0.0001$ \\
\hline \multirow[t]{3}{*}{ Work exposure } & Low & 1 & $<0.0001$ & 1 & $<0.0001$ \\
\hline & Intermediate & $2.20[1.39-3.45]$ & $<0.001$ & $2.60[1.43-4.71]$ & $<0.01$ \\
\hline & High & $3.10[1.99-4.84]$ & $<0.0001$ & $3.91[2.24-6.80]$ & $<0.0001$ \\
\hline Manual hobbies & - & $1.75[1.25-2.44]$ & $<0.01$ & $1.78[1.28-2.47]$ & $<0.01$ \\
\hline \multirow[t]{6}{*}{ Personal factors } & Familial history of Dupuytren's disease & $4.61[3.02-7.03]$ & $<0.0001$ & - & - \\
\hline & History of diabetes mellitus & $1.95[0.97-3.93]$ & 0.06 & - & - \\
\hline & History of epilepsy* & $5.08[1.63-15.78]$ & $<0.01$ & - & - \\
\hline & History of hand trauma & $1.58[1.63-2.30]$ & $<0.05$ & - & - \\
\hline & Alcohol consumption $\geq 5$ drinks /day & $1.44[1.01-2.05]$ & $<0.05$ & - & - \\
\hline & Any personal factors & - & - & $4.05[1.94-8.43]$ & $<0.01$ \\
\hline \multirow[t]{3}{*}{ Interaction terms } & Low work exposure*personal factors & - & - & 1 & 0.74 \\
\hline & Intermediate work exposure* personal factors & - & - & $0.78[0.32-1.91]$ & 0.59 \\
\hline & High work exposure ${ }^{*}$ personal factors & - & - & $0.71[0.30-1.69]$ & 0.42 \\
\hline
\end{tabular}

Table IV. Potential risk factors for Dupuytren's disease in multivariate analysis based on logistic models.

The first model ("detailed model") included age, work exposure, manual hobbies and each personal factor. The second model ("interaction model") included age, work exposure, manual hobbies, any personal factors, and interactions terms between any work exposure and any personal factors.

$a O R=$ adjusted odds ratios, $C I=$ confidence interval

*or anticonvulsant drug intake 


\title{
Inserm
}

\author{
Insilitut natlona1

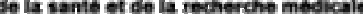 \\ Unité 687 \\ Santé publique et épidémiologie \\ des déterminants professionnels \\ et sociaux de la santé \\ Hôpital National de Saint-Maurice \\ 14 rue du Val d'Osne \\ 94415 SAINT MAURICE CEDEX \\ 窎 $0145183874 / 50$ \\ 包 0145183889
}

$2^{\text {nd }}$ October, 2007

Sir,

Please find enclosed the revised version of our paper entitled "Dupuytren's disease: personal factors and occupational exposure", to be submitted for publication in American Journal of Industrial Medicine, as a brief report.

We previously though the interaction tests between personal factors and occupational exposure do not improve the paper. However, considering the reviewer consideration, we give now all the results of the interaction in another table (to stay clear.)

Sincerely yours

Alexis Descatha, M.D. Ph.D

Correspondence and reprints: Alexis Descatha, Unité de pathologie professionnelle, Hôpital Raymond Poincaré AP-HP, F-92380 Garches, France

Tel: +33 (1) 47107754 ; Fax: +33 (1) 47107768 ;

email: alexis. descatha@rpc. aphp.fr

(i) This manuscript has not been submitted nor is under consideration for publication by another Journal

(ii) No financial or other relationship might lead to a conflict of interest

(iii) The appropriate ethics committee (CNIL) had been contacted. Taking into account that no identification was needed (cross-sectional design) in a common working context, no supplementary registration was thus needed. The study has been therefore performed in accordance of ethical standards.

(iv) Word count (from introduction to acknowledgments) $=2427$ words

(v) The manuscript has been read and approved by all the authors. All authors believe that manuscript is an honest work.
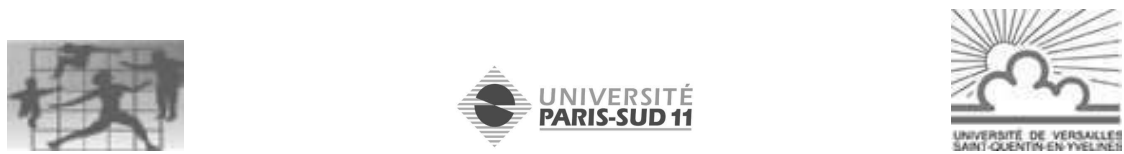
Reviewing: 1

Comments to the Author

9-28-07

Unfortunately, some confusion remains about the issue of the Occupational Exposure $\mathrm{X}$ Personal Factors interactions. The text on page 6, lines 37-39 states, "and all the interaction tests between these factors were not significant. This implies that the effects can be considered as multiplicative." In the revised Table III, however, neither the "detailed model" nor the "interaction model" includes those interactions, which are understood from the text and Table II to include:

Familial History*Intermediate Work Exposure

Familial History*High Work Exposure

History of Diabetes*Intermediate Work Exposure

History of Diabetes*High Work Exposure

History of Hand Trauma*Intermediate Work Exposure

History of Hand Trauma*High Work Exposure

Alcohol Consumption*Intermediate Work Exposure

Alcohol Consumption*High Work Exposure

It is noted in Table III that the interaction model used the summary measure "any personal factors" in testing for Exposure X Personal Factors interactions. This suggests that the specific interactions listed above were not included in the model. If they were not, then the statement on page 6 "and all the interaction tests between these factors were not significant" should be removed or changed to something like, "As shown in Table III, the interactions between 'Occupational Exposure' (Intermediate and High) and 'Any Personal Factors' were not significant." In any case, some editing should be done to achieve consistency between the discussion in the text and the statistics presented in the table.

Response 1. We had previously omitted all the interaction tests between personal factors and occupational exposure, considering these results do not improve the paper.

However, it seems that some confusion could be remaining. We thus added another table (Table III) with all the interaction tests. We think now the discussion in the text and the statistics presented in the table are fully consistent.

Finally, regarding the interaction terms in Table III, the p value is missing from the last row (High work exposure*personal factors).

Response 2. In fact, this was the global test involving interaction between work exposure and personal factors. To be as clear as possible, we added the $p$ value for each level (such as the rows above to be homogenous). 
